Jurnal Ilmiah Ibnu Sina, 6(2), Oktober 2021, 242-251

p-ISSN: 2502-647X; e-ISSN: 2503-1902

\title{
SOSIOEKONOMI, PENGETAHUAN PENYAKIT DIARE DAN PENGETAHUAN SWAMEDIKASI DIARE PADA IBU BALITA DI YOGYAKARTA
}

\author{
Faridah Baroroh*, Ana Hidayati, Siti Nurbayanti, Intan Tin Sari, Atikah \\ Zain, Redy, Siwi Retnaning Dyahayu \\ Fakultas Farmasi, Universitas Ahmad Dahlan Yogyakarta \\ *Email: faridah@pharm.uad.ac.id
}

Artikel diterima: 10 Juli 2021; Disetujui: 25 Agustus 2021

DOI: https://doi.org/10.36387/jiis.v6i2.715

\begin{abstract}
ABSTRAK
Prevalensi diare di Indonesia tertinggi terdeteksi pada anak balita. Terdapat hubungan bermakna faktor ekonomi dan pengetahuan ibu dengan kejadian diare pada balita. Terdapat hubungan bermakna tingkat pengetahuan terhadap tindakan swamedikasi diare akut. Tujuan penelitian untuk mengetahui apakah ada perbedaan tingkat pengetahuan penyakit diare dan pengetahuan swamedikasi diare sebelum dan setelah edukasi, dan apakah terdapat hubungan sosioekonomi dan pengetahuan penyakit diare terhadap pengetahuan swamedikasi diare. Metode penelitian pre-exprimental design tipe one group pretest-posttest dengan subyek penelitian 504 ibu balita di Daerah Istimewa Yogyakarta, Indonesia. Data dikumpulkan dengan daftar pertanyaan yang tervalidasi, yaitu data sosioekonomi (pendidikan, pekerjaan, pendapatan), pengetahuan penyakit diare dan pengetahuan swamedikasi diare. Dilanjutkan edukasi dan posttest menggunakan daftar pertanyaan yang sama. Analisis data secara analitik untuk mengetahui perbedaan pengetahuan dan hubungan sosioekonomi terhadap pengetahuan penyakit diare dan pengetahuan swamedikasi diare. Hasil penelitian menunjukkan sosioekonomi (pendidikan menengah-tinggi 76\%, tidak bekerja 71\%, 62\% pendapatan rendah). Terdapat hubungan signifikan $(\mathrm{p}<0,005)$ tingkat pendidikan dengan tingkat pengetahuan penyakit diare dan swamedikasi diare. Tidak ada hubungan signifikan $(p>0,005)$ status pekerjaan dan pendapatan dengan tingkat pengetahuan penyakit diare dan swamedikasi diare. Ada hubungan signifikan $(\mathrm{p}<0,005)$ tingkat pengetahuan penyakit diare dengan tingkat pengetahuan swamedikasi diare. Ada perbedaan signifikan $(\mathrm{p}=0.000)$ tingkat pengetahuan penyakit diare dan pengetahuan swamedikasi diare sebelum dan setelah edukasi. Kesimpulan ada perbedaan tingkat pengetahuan penyakit diare dan pengetahuan swamedikasi diare sebelum dan setelah edukasi, dan terdapat hubungan sosioekonomi (tingkat pendidikan) dan pengetahuan penyakit diare terhadap pengetahuan swamedikasi diare.
\end{abstract}

Kata kunci: sosioekonomi, pengetahuan, swamedikasi, diare. 
Jurnal Ilmiah Ibnu Sina, 6(2), Oktober 2021, 242-251

p-ISSN: 2502-647X; e-ISSN: 2503-1902

\begin{abstract}
In Indonesia, the prevalence of diarrhea is highest among children under five. Economic factors and maternal knowledge are, in this case, significantly related to diarrhea incidence, and the latter substantially defines self-medication measures taken for acute diarrhea treatment. The research was intended to determine whether or not the knowledge level in the pre and post education were different, and to determine the extent to which socioeconomic conditions and diarrheal knowledge formed comprehension of such treatment. For this purpose, it employed a one group pretest-posttest pre-exprimental design study with 504 research subjects, namely, mothers of children under five in the Special Region of Yogyakarta, Indonesia. Data were collected using a validated questionnaire consisting of items on socioeconomic details (education, employment, income), diarrheal knowledge, and relevant self-medication knowledge. Afterward, education and post-test were conducted using the same list of questions. Analytical techniques were carried out to identify how significant socioeconomic characteristics determined knowledge of diarrheal disease and self-medication. Results showed that, socioeconomically, a large proportion of research subjects attained secondary to tertiary education (76\%), were unemployed (71\%), and earned low income (62\%). Educational attainment was found to be significantly related to levels of knowledge of diarrheal disease and self-medication ( $p<0.005)$, but employment status and income were not ( $p>0.005)$. Analysis results also indicate a significant relationship $(p<0.005)$ between the level of knowledge of diarrheal disease and that of diarrheal self-medication. The test results showed knowledge level in the pre and post education were different $(p=0.000)$. Overall, there is a difference in the level of knowledge in pre and post education, and socioeconomic status (i.e., level of education) and diarrheal knowledge is significantly related to diarrheal self-medication knowledge.
\end{abstract}

Keywords: socioeconomic, knowledge, silf-medication, diarrhea.

\section{PENDAHULUAN}

Prevalensi diare di Indonesia tersebar di semua kelompok umur $(6,8 \%)$ dengan prevalensi tertinggi terdeteksi pada anak balita (1-4 tahun) yaitu 11\% (Kemenkes 2018). Diare merupakan urutan kedua terbesar setelah hipertensi dari 10 besar penyakit di puskesmas di D.I Yogyakarta tahun 2019, kasus diare terjadi pada 28,3\% dari jumlah balita.

Diare merupakan penyebab kematian kedua setelah pneumonia pada balita (Dinkes, 2020).

Faktor sosial ekonomi berpengaruh signifikan terhadap kejadian diare pada balita, dan karakteristik ibu merupakan indikator pengaruh tertinggi (Sumampouw et al., 2019). Dengan demikian faktor 
Jurnal Ilmiah Ibnu Sina, 6(2), Oktober 2021, 242-251

p-ISSN: 2502-647X; e-ISSN: 2503-1902

ekonomi dan pengetahuan ibu terdapat hubungan yang bermakna $(\leq 0,05)$ dengan kejadian diare pada balita usia 1-5 tahun (Febrianti, 2019). Selain itu jumlah anak balita, usia anak, pendidikan ibu, dan status ekonomi juga berhubungan signifikan dengan diare pada anak (Woldu et al., 2016).

Kejadian diare pada balita usia 1-5 tahun di puskesmas juga berhubungan signifikan dengan dengan beberapa faktor, yaitu faktor gizi $(p=0.000)$, faktor makanan $(p=0.000)$, faktor sosial ekonomi (pendidikan orangtua $(p=0.004)$, penghasilan orangtua $(p=0.038)$, dan faktor lingkungan $\quad(p=0.000)$ (Maidartati \& Anggraeni 2017). Pengetahuan ibu balita tentang penyebab, penularan, dan pencegahan diare sebesar $37,5 \%$, dan $62,9 \%$, dengan demikian ibu balita tersebut dikategorikan memiliki sikap yang baik tentang penyebab, penularan, dan pencegahan penyakit diare. Meskipun sumber air di masyarakat, ataupun wadah penampungan air, merupakan prediktor morbiditas diare, tetapi pengetahuan ibu tetap menjadi prediktor kuat morbiditas diare dengan hasil analisis regresi logistik sebagai berikut $(\mathrm{OR}=8.4, \mathrm{CI}$ 3.59-31.85; OR = 2.2, CI 1.02-4.89; dan $\mathrm{OR}=3.62$, CI 1.23-4,71 masingmasing) (Merga \& Alemayehu 2015).

Mayoritas (82,6\%) memilih pengobatan di rumah sebagai penanganan awal diare (Joseph et al., 2016). Begitu juga perawatan diare diberikan di rumah sebanyak 50,4\% lebih banyak dibandingkan perawatan di puskesmas sebanyak 27\% (Ekpo, 2016). Pengetahuan manajemen diare di rumah bagi ibu pengasuh anak, sebanyak $56,2 \% \quad$ memiliki pengetahuan baik. Dimana tingkat pengetahuan berhubungan bermakna dengan tingkat pendidikan, status pekerjaan, dan sumber informasi tentang diare. Praktek penatalaksanaan diare di rumah sebanyak $37,6 \%$ ibu pengasuh anak telah melakukan. Tingkat praktik pengobatan sendiri pada diare berhubungan dengan sumber informasi tentang diare, usia, dan tingkat pendidikan (Fikire et al., 2020). Keterlambatan dalam pengobatan penyakit diare, diantaranya dipengaruhi oleh tingkat 
pendidikan ibu atau pengasuh anak (Desta et al., 2017).

Terdapat hubungan yang bermakna $(0,000)$ antara tingkat pengetahuan terhadap tindakan swamedikasi diare akut. Tingkat pengetahuan baik $(44,5 \%)$, cukup baik $(55,0 \%)$ dengan $52,5 \%$ tindakan tepat swamedikasi diare akut (Vitria Laily 2019). Begitu juga terdapat perbedaan signifikan $(p<0,05)$ tingkat pengetahuan pre-test dengan post-test yang menunjukkan adanya hubungan konseling terhadap tingkat pengetahuan ibu pada terapi diare balita (Khaerani et al., 2018).

\section{METODE PENELITIAN}

Penelitian ini dilaksanakan setelah mendapatkan persetujuan etik penelitian nomor 011911107 dari komite etik penelitian Universitas Ahmad Dahlan Yogyakarta.

Metode penelitian ini adalah pre-exprimental design tipe one group pretest-posttest yang dilakukan pada ibu balita di lima wilayah di Daerah Istimewa Yogyakarta (DIY). Data independent variabel yaitu data sosioekonomi diambil pada saat pre edukasi, sedangkan data dependent yaitu data pengetahuan diambil pada saat pre dan post edukasi. Alat untuk pengumpulan data menggunakan daftar pertanyaan yang telah dilakukan proses validasi. Tahap pertama yaitu sebelum edukasi, dilakukan pretest untuk menguji kemampuan awal subjek penelitian. Data yang diperoleh selain data sosioekonomi (tingkat pendidikan, status pekerjaan, tingkat pendapatan), juga data pengetahuan penyakit diare dan pengetahuan swamedikasi diare. Tahap kedua peserta diberikan edukasi tentang penyakit diare dan swamedikasi diare. Tahap terakhir dilakukan posttest menggunakan daftar pertanyaan yang sama, dengan tujuan untuk mengetahui apakah ada perbedaan pengetahuan sebelum dan setelah edukasi.

Analisis data dilakukan secara deskriptif untuk mengetahui tingkat pengetahuan penyakit diare dan pengetahuan swamedikasi diare. Analisis data secara analitik untuk mengetahui apakah ada perbedaan yang signifikan pengetahuan penyakit diare dan swamedikasi diare sebelum dan setelah edukasi. Selain itu juga dianalisis untuk mengetahui 
Jurnal Ilmiah Ibnu Sina, 6(2), Oktober 2021, 242-251

p-ISSN: 2502-647X; e-ISSN: 2503-1902

hubungan antara sosioekonomi (pendidikan, pekerjaan, pendapatan) terhadap pengetahuan penyakit diare dan pengetahuan swamedikasi diare.

\section{HASIL DAN PEMBAHASAN}

Penelitian ini melibatkan 504 responden yang memenuhi kriteria inklusi dan eksklusi, data hasil penelitian diantaranya adalah data sosioekonomi, pengetahuan penyakit diare dan pengetahuan swamedikasi diare.

Tabel 1. Sosioekonomi dan

\begin{tabular}{lcc}
\multicolumn{3}{c}{ pengetahuan } \\
\hline Sosioekonomi & $\mathrm{N}$ & $\%$ \\
\hline Tingkat Pendidikan & & \\
1. Dasar & 120 & 24 \\
2. Menengah- & 384 & 76 \\
$\quad$ Tinggi & & \\
Status Pekerjaan & & \\
1. Tidak bekerja & 356 & 71 \\
2. Bekerja & 148 & 29 \\
Pendapatan & & \\
1. Rendah & 310 & 62 \\
2. Tinggi & 194 & 38 \\
Pengetahuan penyakit diare & & \\
1. Kurang & 121 & 24 \\
2. Baik & 383 & 76 \\
Pengetahuan swamedikasi diare & \\
1. Kurang & 211 & 42 \\
2. Baik & 293 & 58 \\
\hline
\end{tabular}

Hasil penelitian pada tabel 1 menunjukkan kondisi sosioekonomi dari responden, untuk tingkat pendidikan $76 \%$ adalah lulusan pendidikan menengah-tinggi. Tingkat pendidikan ibu berhubungan

signifikan dengan kejadian diare pada anak (Woldu et al., 2016) dan keterlambatan pengobatan diare (Desta et al., 2017). Dengan tingkat pendidikan ibu balita yang sebagian besar $(76 \%)$ pada kategori menengahtinggi tersebut juga menunjukkan bahwa pengetahuan tentang penyakit diare juga dalam kategori baik (76\%), dan pengetahuan swamedikasi diare dalam kategori baik (58\%). Begitu juga hasil penelitian di Ethiopia yang menunjukkan 63,6\% ibu memiliki pengetahuan baik tentang penanganan diare meskipun baru $45,9 \%$ yang dapat melakukan praktik penanganan diare dengan baik (Amare et al., 2014), bahwa sikap dan praktik ibu kurang memuaskan tentang pencegahan dan penatalaksanaan penyakit diare balita berbasis rumah (Workie \& Hrifabdilahi, 2018). Berbeda halnya dengan penelitian di Kelurahan Korong Gadang dimana $70 \%$ pengetahuan ibu tentang penanganan diare pada balita termasuk dalam kategori kurang (Arsurya \& Rini, 2017). Ibu balita tidak bekerja sebanyak $71 \%$, dan $62 \%$ termasuk kategori tingkat pendapatan rendah. Seperti kita ketahui bahwa 
Jurnal Ilmiah Ibnu Sina, 6(2), Oktober 2021, 242-251

p-ISSN: 2502-647X; e-ISSN: 2503-1902

sosial ekonomi berpengaruh dan berhubungan signifikan terhadap kejadian diare pada balita (Sumampouw et al., 2019).

Tabel 2. Hubungan sosioekonomi dengan pengetahuan penyakit diare

\begin{tabular}{|c|c|c|c|}
\hline \multirow[t]{2}{*}{ Sosioekonomi } & \multicolumn{2}{|c|}{$\begin{array}{c}\text { Pengetahuan } \\
\text { penyakit diare }\end{array}$} & \multirow{2}{*}{$\begin{array}{c}\text { Pvalue } \\
\text { (OR;95\% } \mathrm{CI})\end{array}$} \\
\hline & Kurang & Baik & \\
\hline \multicolumn{4}{|l|}{ Tingkat Pendidikan } \\
\hline 1. Dasar & 55 & 65 & 0.000 \\
\hline $\begin{array}{l}\text { 2. Menengah- } \\
\text { Tinggi }\end{array}$ & 66 & 318 & $\begin{array}{c}(4.077 ; 2.609- \\
6.371)\end{array}$ \\
\hline \multicolumn{4}{|l|}{ Status Pekerjaan } \\
\hline \multirow{2}{*}{$\begin{array}{l}\text { 1. Tidak bekerja } \\
\text { 2. Bekerja }\end{array}$} & 91 & 265 & 0.249 \\
\hline & 30 & 118 & $\begin{array}{c}(1.351 ; 0.847- \\
2.153)\end{array}$ \\
\hline \multicolumn{4}{|l|}{ Pendapatan } \\
\hline 1. Rendah & 73 & 237 & 0.843 \\
\hline 2. Tinggi & 48 & 146 & $\begin{array}{c}(0.937 ; 0.616- \\
1.424)\end{array}$ \\
\hline
\end{tabular}

Hasil analisa hubungan antara sosioekonomi dan pengetahuan penyakit diare pada tabel 2, menunjukkan bahwa ada hubungan yang signifikan $(\mathrm{p}<0,005)$ antara tingkat pendidikan dengan tingkat pengetahuan penyakit diare. Tingkat pengetahuan berhubungan bermakna dengan tingkat pendidikan (Fikire et $a l .$, 2020). Tingkat pendidikan ibu balita menjadi prediktor kuat terhadap pengetahuan penyakit diare $(\mathrm{OR}=4.077, \quad$ CI $\quad 2.609-6.371)$. Pengetahuan ibu menjadi prediktor kuat morbiditas diare $(\mathrm{OR}=3.62, \mathrm{CI}$ 1.23-4,71) (Merga \& Alemayehu 2015). Tidak ada hubungan yang signifikan $(\mathrm{p}>0,005)$ antara status pekerjaan dan pendapatan dengan tingkat pengetahuan penyakit diare. Demikian halnya hasil penelitain tentang faktor sosiodemografis terhadap ibu dalam mencegah diare pada anak, yang menunjukkan bahwa tidak ada hubungan antara status pekerjaan ibu dengan pencegahan diare pada anak-anak (Andrade et al., 2015) Hal ini berbeda dengan penelitian (Fikire et al., 2020) yang menunjukkan bahwa tingkat pengetahuan berhubungan bermakna dengan tingkat pendapatan.

Tabel 3. Hubungan sosioekonomi dengan pengetahuan swamedikasi

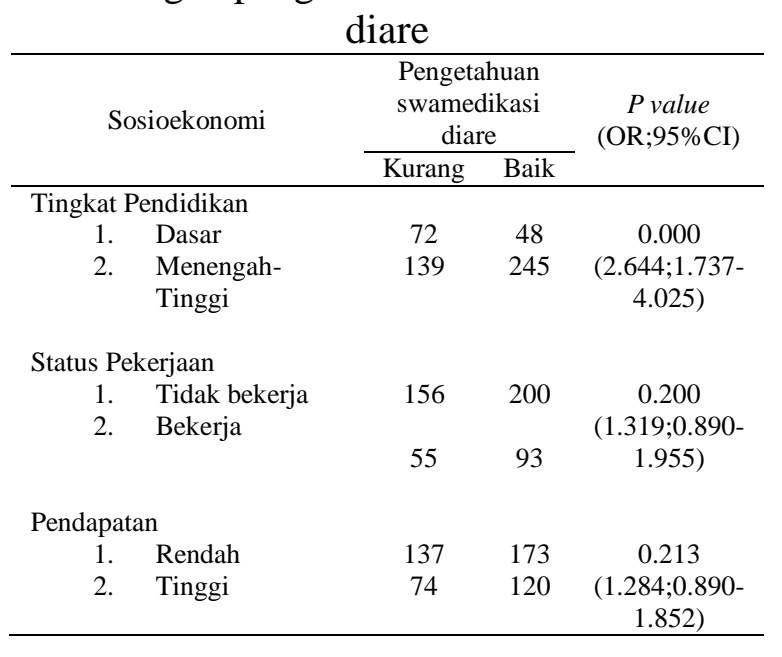

Hasil analisa hubungan antara sosioekonomi dan pengetahuan swamedikasi diare pada tabel 3, menunjukkan bahwa ada hubungan 
Jurnal Ilmiah Ibnu Sina, 6(2), Oktober 2021, 242-251

p-ISSN: 2502-647X; e-ISSN: 2503-1902

yang signifikan $(\mathrm{p}<0,005)$ antara tingkat pendidikan dengan tingkat pengetahuan swamedikasi diare. Tingkat pendidikan berhubungan bermakna dengan tingkat pengetahuan swamedikasi diare (Robiyanto et al., 2018) dan keterlambatan pengobatan diare (Desta et al., 2017). Tingkat pendidikan ibu balita menjadi prediktor kuat terhadap pengetahuan swamedikasi diare $(\mathrm{OR}=2.644, \mathrm{CI}$ 1.737-4.025). Pengetahuan ibu menjadi prediktor kuat morbiditas diare $(\mathrm{OR}=3.62, \mathrm{CI} 1.23-4,71)$ (Merga \& Alemayehu, 2015). Tidak ada hubungan yang signifikan $(p>0,005)$ antara status pekerjaan dan pendapatan dengan tingkat pengetahuan swamedikasi diare. Hal ini berbeda dengan tingkat pengetahuan berhubungan bermakna dengan tingkat pendapatan (Fikire et al., 2020).

Tabel 4. Hubungan pengetahuan penyakit diare dengan swamedikasi

\begin{tabular}{cccc}
\multicolumn{4}{c}{ diare } \\
\hline \multirow{2}{*}{$\begin{array}{l}\text { Pengetahuan } \\
\text { penyakit } \\
\text { diare }\end{array}$} & $\begin{array}{c}\text { Pengetahuan } \\
\text { swamedikasi } \\
\text { diare }\end{array}$ & $\begin{array}{c}P \text { P value } \\
\text { (OR;95\%CI })\end{array}$ \\
\cline { 2 - 3 } & Kurang & Baik & \\
\hline$\quad$ Kurang & 77 & 44 & 0.000 \\
$\quad$ Baik & 134 & 249 & $(3.252 ; 2.124-$
\end{tabular}
4.978) 
Jurnal Ilmiah Ibnu Sina, 6(2), Oktober 2021, 242-251

p-ISSN: 2502-647X; e-ISSN: 2503-1902

pengetahuan penyakit diare dan

pengetahuan swamedikasi diare

sebelum dan setelah edukasi. Hal ini

sama dengan penelitian (Khaerani et

al., 2018) yang menunjukkan ada

perbedaan pengetahuan sebelum dan setelah konseling. Begitu juga penelitian di Kenya menunjukkan ada peningkatan yang signifikan dalam pengetahuan tentang diare dan pengobatannya setelah pelatihan (Ross-Degnan et al., 1996) Terdapat peningkatan pengetahuan dan sikap ibu dalam tatalaksana diare balita di Ungaran timur Kabupaten Semarang setelah pendidikan kesehatan (Adimayanti et al., 2017). Dengan demikian diperlukan edukasi tentang penyakit diare pada ibu yang memiliki balita untuk meningkatkan pengetahuan swamedikasi diare pada balita.

Tabel 5. Pengetahuan Sebelum dan Setelah Edukasi

\begin{tabular}{lccc}
\hline \multicolumn{1}{c}{ Pengetahuan } & $\mathrm{N}$ & $\%$ & $\begin{array}{c}p \\
\text { value }\end{array}$ \\
\hline $\begin{array}{l}\text { Penyakit diare } \\
\text { Sebelum edukasi }\end{array}$ & & & \\
$\quad$ Kurang & 121 & 24 & \\
$\quad$ Baik & 383 & 76 & 0.000 \\
Setelah edukasi & & & \\
$\quad$ Kurang & 23 & 5 & \\
$\quad$ Baik & 481 & 95 &
\end{tabular}

Swamedikasi diare

Sebelum edukasi

0.000

\begin{tabular}{lcc} 
Kurang & 211 & 42 \\
Baik & 293 & 58 \\
Setelah edukasi & & \\
Kurang & 87 & 17 \\
Baik & 417 & 83 \\
\hline
\end{tabular}

\section{KESIMPULAN}

Kesimpulan

penelitian menunjukkan ada perbedaan signifikan $\quad(p=0.000) \quad$ tingkat pengetahuan penyakit diare dan pengetahuan swamedikasi diare sebelum dan setelah edukasi, dan terdapat hubungan signifikan $(p=0,000) \quad$ antara sosioekonomi (tingkat pendidikan) dan pengetahuan penyakit diare terhadap pengetahuan swamedikasi diare pada ibu balita di Daerah Istimewa Yogyakarta (DIY).

\section{UCAPAN TERIMA KASIH}

Terimakasih kepada Universitas Ahmad Dahlan yang telah mendanai penelitian ini melalui hibah penelitian tahun 2020/2021.

\section{DAFTAR PUSTAKA}

Adimayanti E, Haryani S, Astuti, Ana Puji. 2017. "Pengaruh Pendidikan Kesehatan Terhadap Pengetahuan Dan Sikap Ibu Dalam Tatalaksana Diare Balita Di Wilayah Kalongan Kecamatan Ungaran Timur Kabupaten Semarang." Jurnal Ilmiah Kesehatan Ar-Rum 
Jurnal Ilmiah Ibnu Sina, 6(2), Oktober 2021, 242-251

p-ISSN: 2502-647X; e-ISSN: 2503-1902

Salatiga 2(1): 32-38.

Amare D, Dereje B, Kassie B, Tessema M, Mullu G, Alene B, Aznamariam Ayele. 2014. "Maternal Knowledge and Practice Towards Diarrhoea Management in Under Five Children in Fenote Selam Town, West Gojjam Zone, Amhara Regional State, Northwest Ethiopia, 2014." Journal of Infectious Diseases and Therapy 2(6): 1-9.

Andrade L, Mendes E, Vasconcelos I, Joventino E, Almeida P, Ximenes, Lorena Barbosa. 2015. "Socio-Demographic Factors Relating to Mothers' Self-Efficacy in Preventing Childhood Diarrhea: A Longitudinal Study." Online Brazilian Journal of Nursing 14(1): 62-70.

Arsurya Y, Rini EA, Abdiana Abdiana. 2017. "Hubungan Tingkat Pengetahuan Ibu Tentang Penanganan Diare Dengan Kejadian Diare Pada Balita Di Kelurahan Korong Gadang Kecamatan Kuranji Kota Padang." Jurnal Kesehatan Andalas 6(2): 45256.

Bambungan YM. 2020. "Analisis Faktor-Faktor Yang Berhubungan Dengan Swamedikasi Diare Pada Masyarakat Di Distrik Mariat Kabupaten Sorong." GLOBAL HEALTH SCIENCE 5(2): 7377.

Desta, Bogale Kassahun, Nega Tezera Assimamaw, and Tesfaye Demeke Ashenafi. 2017.
"Knowledge, Practice, and Associated Factors of HomeBased Management of Diarrhea among Caregivers of Children Attending Under-Five Clinic in Fagita Lekoma District, Awi Zone, Amhara Regional State, Northwest Ethiopia, 2016." Nursing Research and Practice.

Dinkes. 2020. Profil Kesehatan Daerah Istimewa Yogyakarta Tahun 2019. Dinas Kesehatan Daerah Istimewa Yogyakarta.

Ekpo, Oluranti. 2016. "Careseeking for Childhood Diarrhoea at the Primary Level of Care in Communities in Cross River State, Nigeria." Journal of Epidemiology and Global Health 6(4): 303-13.

Febrianti, Arly. 2019. "Hubungan Faktor Sosial Ekonomi, Pengetahuan Ibu Tentang Lingkungan Sehat Dan Diare Dengan Kejadian Diare Pada Balita Usia 1-5 Tahun Di Puskesmas Pembina Palembang." Journal of Midwifery and Nursing 1(3, Aug): 18-23.

Fikire, Alemayehu, Gistane Ayele, and Desta Haftu. 2020. "Determinants of Delay in Care Seeking for Diarrheal Diseases among Mothers/Caregivers with under-Five Children in Public Health Facilities of Arba Minch Town, Southern Ethiopia; 2019." PLOS ONE.

Joseph, Nitin et al. 2016. "Prevalence, Risk Factors and Treatment Practices in Diarrhoeal Diseases in South India." Environmental Health and Preventive Medicine 
Jurnal Ilmiah Ibnu Sina, 6(2), Oktober 2021, 242-251

p-ISSN: 2502-647X; e-ISSN: 2503-1902

21(4): 248-57.

Kemenkes, R I. 2018. Riset

Kesehatan Dasar. Jakarta:

Badan penelitan dan pengembangan kesehatan, Kemenkes RI, Jakarta, 94-100.

Khaerani, Surya Ningsi, and Andi Try

Resti Fauziah Sahib. 2018.

"Efek Konseling Terhadap

Tingkat Pengetahuan Ibu Pada

Terapi Diare Balita." Media

Farmasi 15(2): 51-55.

Maidartati, and Rima Dewi Anggraeni. 2017. "FaktorFaktor Yang Berhubungan Dengan Kejadian Diare Pada Balita (Studi Kasus : Puskesmas Babakansari)." Jurnal Keperawatan BSI 5(2): 110-20.

Merga, Nigatu, and Tadesse Alemayehu. 2015. "Knowledge, Perception, and Management Skills of Mothers with underFive Children about Diarrhoeal Disease in Indigenous and Resettlement Communities in Assosa District, Western Ethiopia." Journal of Health, Population and Nutrition 33(1): 20-30.

Robiyanto, Rosmimi M, Untari, Eka Kartika. 2018. "Analisis Pengaruh Tingkat Pengetahuan Masyarakat Terhadap Tindakan Swamedikasi Diare Akut Di Kecamatan Pontianak Timur." Jurnal Pendidikan 16(1): 13545.

Ross-Degnan, D et al. 1996. "The
Impact of Face-to-Face Educational Outreach on Diarrhoea Treatment in Pharmacies." Health policy and planning 11(3): 308-318.

Sumampouw, Oksfriani Jufri, Jeini Ester Nelwan, and Adisti Aldegonda Rumayar. 2019. "Socioeconomic Factors Associated with Diarrhea among Under-Five Children in Manado Coastal Area, Indonesia." Journal of Global Infectious Diseases.

Vitria Laily, Henni Wati. 2019. "Hubungan Tingkat Pengetahuan Dengan Tindakan Swamedikasi Diare Akut Di Kabupaten Nganjuk." Java Health Jounal 6(1): 1-10.

Woldu, Wondwoson, Bikes Destaw Bitew, and Zemichael Gizaw. 2016. "Socioeconomic Factors Associated with Diarrheal Diseases among Under-Five Children of the Nomadic Population in Northeast Ethiopia." Tropical Medicine and Health.

Workie H, Sharifabdilahi A, Addis E. 2018. "Mothers' Knowledge, Attitude and Practice towards the Prevention and Home-Based Management of Diarrheal Disease among under-Five Children in Diredawa, Eastern Ethiopia, 2016: A CrossSectional Study." $B M C$ Pediatrics 18(358): 1-9. 